\title{
PEDAGOGIA 2.0 NA WEB SOCIAL E O SEU IMPACTO NO AUTOCONCEITO DE ESTUDANTES DE PÓS-GRADUAÇÃO
}

\author{
José António Moreira*
}

\begin{abstract}
RESUMO
A vertiginosa evolução das tecnologias de informação e da comunicação (TIC) e o advento da Internet propiciaram o surgimento de uma sociedade em rede marcada por mudanças acentuadas na economia, impulsionando o nascimento de novos paradigmas, modelos, processos de comunicação educacional e novos cenários de aprendizagem. É precisamente um desses cenários pedagógicos na web social que pretendemos analisar, descrevendo o seu impacto no autoconceito acadêmico de vinte e nove estudantes de pós-graduação, a partir da análise qualitativa das suas perceções e narrativas e tendo como referencial o Modelo Pedagógico Virtual ${ }^{\circledR}$ da Universidade Aberta, Portugal. Os resultados mostram que o design do ambiente, ancorado nos princípios do construtivismo, da autonomia, da flexibilidade, da inclusão e da interação, podem ter efeitos muito positivos no autoconceito acadêmico dos estudantes do ensino superior, em nível das diferentes dimensões consideradas: Motivação, Orientação para a Tarefa, Confiança nas suas Capacidades e Relação com os Colegas. São discutidas as implicações dos resultados encontrados, tanto do ponto de vista de intervenção prática, quanto em termos de investigações futuras.
\end{abstract}

Palavras-Chave: Autoconceito acadêmico. Pedagogia 2.0. Web social.

\section{ABSTRACT \\ PEDAGOGY 2.0 WITHIN THE SOCIAL WEB AND ITS IMPACT ON THE SELF-CONCEPT OF POSTGRADUATE STUDENTS}

The vertiginous evolution of information and communication technologies (ICT) and the advent of the Internet propitiated the emergence of a networked society marked by deep changes in the economy, stimulating the emergence of new paradigms, models, educational communication processes and new learning scenarios. It is precisely one of these pedagogical scenarios within the social web that we intend to analyze, describing its impact on the academic self-concept of twenty-nine graduate students, based on the qualitative analysis of their own perceptions and narratives, and using as a reference point the Open University Virtual Pedagogical Model ${ }^{\circledR}$. The results show that these online environments - whose design is anchored in the principles of constructivism, autonomy, flexibility and interaction - may have very positive effects

\footnotetext{
* Doutor em Ciências da Educação pela Universidade de Coimbra (UC). Professor do Departamento de Educação e Ensino a Distância da Universidade Aberta, Portugal. Diretor da Delegação Regional do Porto da Universidade Aberta, Portugal. Investigador Integrado no Grupo de Políticas e Organizações Educativas e Dinâmicas Educacionais (gruPOEDE) do Centro de Estudos Interdisciplinares do Século XX (CEIS20) da Universidade de Coimbra. Coordenador Científico da Unidade Móvel de Investigação de Estudos do Local (ELO) da Universidade Aberta. Endereço institucional: Rua do Amial, 752, 4200-055 Porto, Portugal.jmoreira@uab.pt
} 
on the academic self-concept of higher education students in the various dimensions taken into consideration: Motivation, Task Orientation, Self-Confidence in their own capabilities and Relationships with peers. The implications of the results are discussed not only from the point of view of practical intervention, but also in terms of future research.

Keywords: Academic self-concept. Pedagogy 2.0. Social web.

\section{RESUMEN}

\section{PEDAGOGÍA 2.0 EN LA WEB SOCIAL Y SU IMPACTO EN LA AUTO- CONCEPCIÓN DE ESTUDIANTES DE POSGRADO}

La vertiginosa evolución de las tecnologías de la información y la comunicación (TIC) y la llegada de la internet propiciaron el surgimiento de una sociedad en red marcada por los cambios acentuados en la economía, impulsando el nacimiento de nuevos paradigmas, modelos, procesos de comunicación educativa y nuevos escenarios de aprendizaje. Es precisamente uno de esos escenarios pedagógicos en la web social que se pretende analizar, describiendo su impacto en el auto-concepto académico de veintinueve estudiantes de posgrado, partiendo de un análisis cualitativo de sus percepciones y narrativas, y teniendo como referencia el Modelo Pedagógico Virtual ${ }^{\circledR}$ de la UniversidadAbierta, Portugal. Los resultados muestran que el diseño del ambiente, anclado en los principios del constructivismo, de la autonomía, de la flexibilidad, de la inclusión y de la interacción, puede tener efectos muy positivo en el auto-concepto académico de los estudiantes de enseñanza superior, dentro de las diferentes dimensiones consideradas: motivación, predisposición hacia las tareas, confianza en sus capacidades y relación con los compañeros. Son discutidas las implicaciones de los resultados encontrados, desde el punto de vista de la intervención práctica y en términos de futuras investigaciones.

Palabras clave: Auto-concepto Académico. Pedagogía 2.0. Web social.

\section{Introdução}

Com a Web 2.0, a ênfase tem sido colocada na aprendizagem em rede e nas potencialidades do designado software social para acesso à informação e ao conhecimento (MOREIRA; JANUÁRIO; MONTEIRO, 2014). Com efeito, hoje, a aprendizagem em espaços com mais "respiração", sem barreiras, nem muros físicos ou virtuais, como as redes sociais, constitui um enorme desafio para a sociedade digital, na medida em que estes ambientes remetem-nos para uma Pedagogia 2.0 e para o paradigma emergente da Educação Aberta.

A Pedagogia 2.0 apresenta-se como a arte ou a ciência de ensinar com ferramentas da web 2.0 e assenta na interseção de três elementos P: Participação em comunidades de rede, Personalização da experiência de aprendizagem e Produtividade relacionada com a criação do conhecimento (LEE; McLOUGHLIN, 2007; McLOUGHLIN; LEE, 2011).

Por sua vez, a Educação Aberta colaborativa em rede tem sido considerada uma filosofia educacional importante para enriquecer a aprendizagem ao longo da vida e tem proporcionado a oportunidade de aceder e de construir conhecimento através das redes sociais. O rápido crescimento dos Recursos Educacionais Abertos (REA) na Web 2.0, promovendo o acesso e uso livre de conteúdos e tecnologias, tem favorecido a construção coletiva do conhecimento com base numa reconstrução colaborativa e redistribuição partilhada, e tem proporcionado mudanças de práticas e formas de aprender que visam a autonomia, a coautoria e a socialização (OKADA, 2014). 
No entanto, importa ter presente que a implementação dessas práticas e formas de aprender deve ser acompanhada de um processo de aferição das mesmas como forma de coleta de informações úteis que permitam julgar a adequação de possíveis soluções práticas.

$\mathrm{O}$ estudo que agora apresentamos visa, pois, analisar o impacto de novos cenários de aprendizagem na web social, no autoconceito acadêmico de estudantes de pós-graduação, nomeadamente no que diz respeito à Motivação, Orientação para a Tarefa, Confiança nas Capacidades e Relação com os Colegas.

\section{Sociedade em Rede, Redes Sociais e Autoconceito Acadêmico}

Castells (2007) designa por informacionalismo o atual modelo desenvolvimento, baseado no princípio de que o sistema produtivo das sociedades informacionais está organizado de modo a que a produtividade seja maximizada através do conhecimento e da proliferação das tecnologias de informação. Por conseguinte, "o informacionalismo visa [...] a acumulação de conhecimentos e maiores níveis de complexidade do processamento da informação" (CASTELLS, 2007, p. 21).

Essa "nova sociedade" informacional é uma sociedade em rede, tendo em conta que as funções e os [atuais] processos dominantes

\section{[...] organizam-se, cada vez mais, em torno de redes e isto representa o auge de uma tendência histórica. As redes constituem a nova morfologia das sociedades e a difusão da sua lógica modifica substancialmente as operações e os resultados dos processos de produção, experiência, poder e cultura. [...] o novo paradigma das tecnologias da informação fornece as bases materiais para a expansão da sua [das redes] penetrabilidade em toda a estrutura social. (CASTELLS, 2007, p. 605).}

$\mathrm{Na}$ verdade, considerar a estrutura social atual implica o reconhecimento das redes e processos sociais complexos, dada a sua natureza dinâmica, aberta, complexa e constante reestruturação e inovação. Esta configuração social, dependente das tecnologias de informação e comunicação e, sobretudo, de um modo diferenciado de comunicar, não só potencia a irreversível globalização econômica, como também, pela forma rápida em que as desig- nadas redes se constituem, reformulam e cessam, consolidam processos localizados que configuram novas pertenças, reforçando identidades. Ou seja, cada indivíduo vai operando sociabilidades diferenciadas ao conectar-se/desconectar-se de diversas redes (grupos) sociais, reformulando, deste modo, as suas vivências em várias esferas da vida.

Este mundo imbricado a larga escala, dado que o tempo e o espaço se comprimem pela força da mediatização tecnológica e pela forma como comunicamos hoje, exige novas habilidades e competências em nível pessoal e em nível da esfera do trabalho (CASTELLS, 2007).

Uma economia global e estruturada na inovação exige, em primeira instância, novas competências por parte dos trabalhadores e, inevitavelmente, uma reconversão do sistema educativo.

Assim, partindo-se de pressuposto de que o novo trabalhador terá de ser flexível, adaptável às mudanças de forma permanente (ao longo da vida) e autônomo mas envolvido, requer-se uma reconversão total do sistema educativo, em todos os seus níveis e domínios. Isto refere-se, certamente, a novas formas de tecnologia e pedagogia, mas também aos conteúdos e organização do processo de aprendizagem.

[...] A política educacional é central em todos os aspectos. Mas não é qualquer tipo de educação ou qualquer tipo de política: educação baseada no modo de aprender a aprender, ao longo da vida, e preparada para estimular a criatividade e a inovação de forma - e com o objectivo de - aplicar esta capacidade de aprendizagem a todos os domínios da vida social e profissional. (CASTELLS, 2005, p. 27).

De fato, o sistema educativo e o subsistema social da aprendizagem não podem ser entendidos como alheios aos (novos) processos produtivos dos (novos) processos sociais. Inevitavelmente, a nova cultura em rede estende-se ao sistema de ensino, e, em paralelo ao que foi dito quanto à estrutura (aprendizagem responsável, ao longo da vida, para garantir a adaptabilidade e flexibilidade exigidas), a extensão das redes como processo e meio educativos equivalerá a integrar no quotidiano dos indivíduos os próprios processos de aprendizagem. Por seu turno, esta extensão e comunhão das sociabilidades no espaço e tempo parecem configurar um caráter inevitável. 
Efetivamente, as redes sociais fazem parte dessa nova cultura, mas não são um fenômeno recente, tampouco surgiram com a web, sempre existiram na sociedade, motivadas pela necessidade que os indivíduos têm de partilhar entre si conhecimentos, informações ou preferências. Porém, como afirma Recuero (2009), as mais recentes descobertas tecnológicas, que propiciaram o surgimento do ciberespaço, permitiram a sua emergência como uma forma dominante de organização social.

Sendo as redes sociais espaços coletivos e colaborativos de comunicação e de troca de informação, podem facilitar a criação e desenvolvimento de comunidades de prática ou de aprendizagem desde que exista uma intencionalidade educativa explícita. Assim, perceber como se pode ensinar e aprender, formal ou informalmente, em espaços abertos e de aprendizagem colaborativa, em redes sociais na internet (RSI), é um dos grandes desafios que se colocam a todos os educadores.

Como sabemos, atualmente, as redes sociais são parte integrante da vida dos nossos estudantes, e entre as mais populares destacam-se o Facebook, LinkedIn, Orkut, Twitter e Youtube, sendo a mais utilizada o Facebook. Foi tendo em conta a crescente utilização desta rede que os professores do Ensino Superior começaram a adotá-la como forma de manter o contato com os estudantes fora da sala de aula (PEMPECK; YERMOLAYEVA; CARVET, 2009).

Com efeito, o Facebook, como recurso ou como ambiente virtual de aprendizagem, possibilita que o professor reinterprete a forma de ensinar e de aprender num contexto mais interativo e participativo. É interessante notar que alguns estudos que compararam o uso do Facebook com sistemas de gestão de aprendizagem, como o Moodle, o Blackboard ou o WebCT, têm revelado que os estudantes preferem comunicar pelo Facebook (CHU; MEULEMANS, 2008; SCHROEDER; GREENBOWE, 2009). Estes resultados evidenciam a atualidade e pertinência do estudo que aqui apresentamos e justifica a relevância de que se produza conhecimento acerca das potencialidades das redes sociais, nomeadamente do Facebook. Isto porque, e destacando as palavras de Basso et al. (2013), o Facebook apresenta-se como um enorme desafio à educação, na medida em que pode proporcionar um processo dinâmico de ensino-aprendizagem do qual os estudantes se sentem parte integrante. Ao fazerem parte desse processo, revelam-se estudantes competentes na arte de aprender, com ações mais autónomas e maior responsabilidade na construção do seu próprio conhecimento (BASSO et al., 2013).

Num contexto educativo de mudanças, emerge, pois, como compromisso fundamental e como construto fundamental nuclear o autoconceito acadêmico, enquanto dimensão promotora e facilitadora da aprendizagem.

$\mathrm{O}$ autoconceito acadêmico refere-se à imagem que o indivíduo desenvolve e tem de si como sujeito envolvido num determinado processo de escolarização e de aprendizagem (ESTEVÃO; ALMEIDA, 1998). Lima e Seco (1990) e Simões e Serra (1987) salientam que o autoconceito acadêmico refere-se às perceções e avaliações das competências que o indivíduo julga possuir para cumprir as exigências inerentes ao processo escolar em que se encontra envolvido, em comparação com outros indivíduos do seu grupo de referência.

Os professores influenciam o desenvolvimento do autoconceito acadêmico do estudante, na medida em que comunicam as suas expetativas em relação ao seu desempenho, podendo influenciá-los de uma maneira negativa ou positiva (URHAHNE et al., 2011). Para além da influência dos professores, a relação com os pares é igualmente importante, visto que é através de um processo de comparação interpessoal que se forma o autoconceito do estudante (BENTO, 1997).

Assim, com o objetivo de analisar o impacto do cenário de aprendizagem desenvolvido na rede social Facebook no autoconceito acadêmico em estudantes de pós-graduação, em facetas como a motivação, a orientação para as tarefas, a confiança nas suas capacidades ou a relação com os pares, desenvolvemos o presente trabalho.

Como quadro concetual tomamos o Modelo Pedagógico Virtual ${ }^{\circledR}$ da Universidade Aberta, Portugal, que se apoia num ensino centrado no estudante e promotor de inclusão digital, baseado na flexibilidade de acesso à aprendizagem (conteúdos e atividades) e na interação diversificada quer entre estudante-docente, quer entre estudante-estudante, quer ainda entre o estudante e os recursos. Neste modelo o estudante é integrado numa comunidade 
de aprendizagem que dispõe de acesso permanente a recursos educacionais abertos, objetos de aprendizagem, e-atividades, debates e partilha de experiências.

Em síntese, a nossa investigação pretende perspectivar possíveis cenários e designs alternativos de aprendizagem, no domínio da pedagogia no ensino superior, estudando o efeito desse modelo no autoconceito acadêmico dos estudantes, sobretudo no que diz respeito à motivação, à orientação para as tarefas, à confiança nas próprias capacidades, relação com os pares, bem como de exploração e aprofundamento das aprendizagens, com reflexo nos resultados esperados.

\section{Metodologia}

A natureza da indagação levou-nos a considerar pertinente uma abordagem como a Design Based Research (DBR), que parte do conceito de design experiments. De acordo com Wang e Hannafin (2005), esta metodologia de pesquisa em educação predispõe-se a realizar investigação rigorosa e reflexiva para testar e aperfeiçoar ambientes de aprendizagem inovadores. Os professores assumem o papel de copesquisadores, contribuindo para o desenvolvimento da teoria do design, a fim de conduzir à implementação das inovações.

Trata-se de uma metodologia que procura pesquisar problemas educativos em contextos reais de atuação pedagógica, com vista à resolução de problemas significativos e práticos, conciliando teoria e prática através de uma ligação colaborativa entre investigadores e profissionais que procuram entender, documentar, interpretar e melhorar a prática educativa.

A DBR está associada a uma epistemologia pragmática que considera a teoria de aprendizagem conseguida de forma colaborativa pelos intervenientes no processo, e cujo objetivo da pesquisa é resolver problemas reais, ao mesmo tempo que permite a construção de princípios de design que podem influenciar decisões futuras.

Com o intuito de suscitar a emergência de dados referentes ao estudo, recorremos a uma técnica de investigação capaz de codificar as declarações semilivres e aparentemente desordenadas: a análise de conteúdo (BARDIN, 1977; VALA, 1986).
Iniciámos a análise de conteúdo procedendo à leitura flutuante da totalidade das respostas ao inquérito com o intuito de alinhar os temas comuns e de detetar particularidades em razão da individualidade dos casos. Posteriormente, iniciamos o processo de sistematização da categorização emergente, procurando respeitar a regra de exaustividade defendida por Bardin (1977), que considera todos os elementos do corpus. Considerando todas as respostas para a categorização e comparação do conteúdo, separamos as unidades de registro do corpus em parágrafos e numerámo-las sequencialmente em virtude do alinhamento das respostas. A análise foi feita em função do quadro de categorias definido, combinando a emergência de novos dados já sugeridos pelo quadro concetual e pela revisão da literatura. Com o intuito de organizar a informação de forma percetível, optamos por codificar os dados baseando-nos em apenas três letras que derivam, basicamente, das iniciais, ou das três primeiras letras da palavra ou do conjunto de três letras significativas.

A nossa amostra foi constituída por um grupo de 29 estudantes de dois cursos de Pós-Graduação da Universidade Aberta, Portugal. O instrumento que serviu de base à coleta de dados foi um inquérito por questionário distribuído presencialmente. Tendo em conta o âmbito e o objetivo do estudo, bem como a análise documental de alguns normativos relevantes no contexto em estudo, inspiramo-nos no Self Concept as a Learner Scale (SCAL), desenvolvido por Waetjen, em 1972, posteriormente adaptado por Veiga (1996) à população portuguesa, para construir o nosso instrumento. Assim, as quatro dimensões que constituem o SCAL foram aquelas que definimos para o nosso instrumento. A primeira - Motivação - faz referência às perceções que o estudante tem de si próprio, relativamente ao gosto e interesse pelas e-atividades desenvolvidas no ambiente virtual de aprendizagem criado na rede social; a segunda - Orientação para a Tarefa - avalia o cuidado com que o estudante realiza as e-atividades no ambiente virtual, referindo-se, essencialmente, ao esforço para fazer bem as atividades indicadas; a terceira - Confiança nas Capacidades - avalia a confiança que o estudante tem nas suas capacidades para desenvolver as atividades online e na expressão das suas ideias nos espaços de comunicação do Facebook; e a quarta - Relação com os Colegas - 
relaciona-se com a sua integração na comunidade virtual de aprendizagem e com a perceção de confiança recebida da comunidade. Com base nestas categorias, definimos uma série de questões abertas que constituíram o corpo do inquérito.

A informação proveniente dos inquéritos será apresentada em quadros, com o objetivo de exemplificar a relevância de algumas das suas opiniões, contendo esses quadros a codificação referente ao número $(\mathrm{N})$ de estudante $(\mathrm{E})$, o número da unidade de registro e o registro com excertos do seu discurso.

\section{Análise dos Resultados}

Antes de passarmos à análise dos resultados, pensamos que é importante referir que a análise dos dados emergentes obedeceu a uma lógica de funcionamento baseada na alternância de duas fases. Numa primeira fase foi realizada uma análise vertical de cada um dos questionários, e na segunda procedemos a uma análise horizontal ou comparativa com recurso ao método da "análise comparativa constante" (MILES; HUBERMAN, 1984), com o intuito de identificar aspectos comuns e distintivos das representações e percepções destes estudantes. Para o efeito apresentaremos a informação em quadros, com o objetivo de exemplificar a relevância de algumas das suas opiniões, contendo esses quadros a codificação referente ao número de estudante (EST), o número da unidade de registro (UR) e o registro com excertos do seu discurso. Pensamos que a escolha deste modelo organizativo da informação permite uma mais adequada visualização do quadro geral representativo das suas conceções.

Assim, na primeira categoria, Motivação, com vinte e nove registros, que comporta as referência às perceções que os estudantes têm de si próprios, relativamente ao gosto e interesse pela metodologia e pelas e-atividades desenvolvidas no Facebook, a classificação das unidades de registro repartiram-se pelas frequências de Motivante $(+)$ e Pouco ou Nada Motivante (-). A primeira, Motivante, foi aquela que recebeu a maioria das referências, vinte registros, o que sugere que esses estudantes consideram este ambiente muito motivante; a segunda, Pouco ou Nada Motivante, com nove registros, traduz, de acordo com estes registros, a incapacidade deste ambiente se apresentar mais estimulante do que um LMS construído especificamente para a aprendizagem.

Quadro 1 - Motivação

\begin{tabular}{|c|c|c|l|}
\hline EST & UR & S & \multicolumn{1}{c|}{ Registro } \\
\hline E2 & 2 & + & $\begin{array}{l}\text { Por não estar muito à vontade na utilização do Facebook, senti a timidez } \\
\text { de quem começa sem segurança. Porém, com o tempo, a motivação foi } \\
\text { aparecendo e foi interessante ver crescer a vontade e o interesse de todos } \\
\text { os dias ir "espreitar" o mural para ler o que se escrevia por lá. }\end{array}$ \\
\hline E4 & 4 & + & $\begin{array}{l}\text { Esta ferramenta de trabalho permitiu aumentar os meus índices de } \\
\text { motivação e empenho, porque consegui, com facilidade, acompanhar as } \\
\text { publicações e comentários dos colegas. Isso incentivou-me a participar } \\
\text { mais no debate. E se durante o dia não conseguia acompanhar as tarefas, } \\
\text { depois tinha a facilidade de acesso à rede social, dando contributos. } \\
\text { Mas além deste recurso, a proximidade por parte do professor, a sua } \\
\text { envolvência e participação ativa e encorajadora e os seus comentários } \\
\text { permitiram e incentivaram a participação e ligação entre os colegas. }\end{array}$ \\
\hline E17 & 17 & + & $\begin{array}{l}\text { Na minha opinião, o ambiente foi muito motivador, porque o acesso } \\
\text { foi feito de uma forma muito rápida e eficaz (tablet, smartphone etc.). } \\
\text { Conforme ia começando um debate, sentia-me motivada para iniciar o } \\
\text { tema, indo pesquisar e estudar para depois inserir o meu comentário e } \\
\text { também para comentar os comentários dos colegas. }\end{array}$ \\
\hline E18 & 8 & - & $\begin{array}{l}\text { A motivação foi apenas relativamente aos conteúdos e não relativamente } \\
\text { à rede social, pois prefiro utilizá-la para questões pessoais. }\end{array}$ \\
\hline E25 & 25 & $\begin{array}{l}\text { Não, senti-me muito mais motivado num ambiente tipo LMS, } \\
\text { direcionado para a aprendizagem e não numa rede social. }\end{array}$ \\
\hline
\end{tabular}

Fonte: Elaborado pelo autor deste artigo. 
Como podemos ver na primeira unidade de registro exemplificativa o estudante E2, que mostrava alguma insegurança inicial, refere que após o início das atividades de aprendizagem sentiu os seus índices de motivação crescerem, indo, inclusive, diariamente "espreitar" o mural e os posts colocados pelos colegas.

Outra estudante, E12, tem uma opinião idêntica, referindo também que:

A opinião que tinha acerca do Facebook era bastante negativa. Já tinha perfil, no entanto utilizava a rede muito poucas vezes. Com a experiência de utilizar esta rede social como um sala de aula virtual fez com que passa-se a dar mais apreço ao espaço. Afinal podem-se tratar coisas interessantes neste espaço virtual. (UR12).

Por sua vez, a estudante EB4, como podemos ver na segunda unidade de registro exemplificativa (UR4), considera que não foi só a forma como o ambiente virtual de aprendizagem estava organizado que contribuiu para o aumento da sua motivação, mas foi também o próprio professor que, com a sua participação ativa e encorajadora, fortaleceu os laços entre os elementos da turma.

Com efeito, uma das potencialidades desses ambientes virtuais de aprendizagem prende-se com a interatividade e interação que se pode estabelecer entre os diferentes participantes. E neste processo de interação, o professor é o responsável por identificar os conhecimentos relevantes, propor experiências que levem ao discurso crítico e à reflexão, diagnosticar e avaliar os resultados de aprendizagem, sendo que o eLearning exige uma maior atenção ao equilíbrio entre o controle e a responsabilidade (GARRISON; ANDERSON, 2005).

Por sua vez a estudante E17, na terceira unidade de registro exemplificativa, considera que este ambiente virtual revelou-se muito estimulante, porque para além do seu acesso ser muito fácil através de dispositivos móveis, permitiu-lhe, de acordo com as orientações do professor, pesquisar, estudar e selecionar informação que lhe possibilitaram construir conhecimento de forma colaborativa.

Essa abordagem é extremamente importante, porque permite que o estudante esteja no centro da sua aprendizagem e tenha uma participação ativa, construindo o seu próprio conhecimento (GOULÃO, 2012). Há uma nova relação entre o conhecimento e a aprendizagem, como se depreende nas palavras da estudante E11: “[...] o ambiente é muito propício à aprendizagem de conteúdos, pois necessitamos de investigar sozinhos para conseguir acompanhar o "debate" (UR11).

É, pois, uma abordagem que encoraja e aceita a autonomia e iniciativa dos estudantes; que encoraja os estudantes a dialogar com o professor e entre si; que os encoraja a resolverem os problemas e perguntarem uns aos outros a solução; que os estimula a assumir responsabilidades e que estimula a discussão e mantém a curiosidade do estudante (MOREIRA; MONTEIRO, 2010).

Também o estudante E15 destaca a importância do papel do professor, referindo que: "O que nos motivou, sobretudo, foi o comprometimento do professor com seus alunos. E nisso não houve falha." (UR15).

E perante essa afirmação, como se deve posicionar o professor? Este deve estar consciente que não se trata apenas de dominar um qualquer instrumento ou um novo sistema de representação de conhecimento, mas sim uma nova cultura de aprendizagem. Isto pressupõe que os professores, mais do que transmitir informação, promovam competências nos seus estudantes, de procura, seleção e interpretação da informação disponível. Nesta sociedade da informação, com as alterações que comporta na aprendizagem e na construção do conhecimento, o professor deve assumir-se, pois, como mediador e facilitador, proporcionando as ajudas educativas adequadas a uma aprendizagem construtivista do estudante (SALMON, 2003).

No cerne da atitude do professor está, pois, a forma como ele encara essa ferramenta, a capacidade que tem em integrá-la de forma oportuna num conjunto de outras estratégias e recursos didáticos ou no aproveitamento que dela retira como método de abordagem ao próprio tema (MOREIRA, 2012).

No entanto, nem todas as afirmações vão no sentido de índices de motivação mais elevados. Como podemos ver na quarta unidade de registro exemplificativa, o estudante E18 afirma que a sua motivação prendeu-se mais aos conteúdos do que ao ambiente educativo, pois prefere utilizar o Facebook na esfera da sua vida privada.

O estudante E25 é mais peremptório, afirmando que a sua motivação é maior num ambiente 
construído especificamente para a o processo de ensino-aprendizagem do que numa rede social. Este testemunho contraria um pouco os estudos já citados (CHU; MEULEMANS, 2008; SCHROEDER; GREENBOWE, 2009), que revelam que os estudantes preferem comunicar pelo Facebook do que por LMS, como o Moodle, o Blackboard ou o WebCT.

Relativamente à segunda categoria, Orientação Para a Tarefa, também com vinte e nove registros, referente às perceções que os estudantes têm de si próprios, no que concerne à sua capacidade de organizar e gerir as e-tarefas no Facebook, a classificação das unidades de registro mostra um número muito elevado de perceções de tendência positiva (vinte e sete), o que indicia, claramente, que os estudantes consideram que conseguiram organizar-se e gerir bem as e-tarefas que tiveram de realizar no Facebook.

Quadro 2 - Orientação para a tarefa

\begin{tabular}{|c|c|c|l|}
\hline EST & UR & S & \multicolumn{1}{c|}{ Registro } \\
\hline E17 & 46 & + & $\begin{array}{l}\text { Senti que toda a unidade curricular estava muito bem organizada, } \\
\text { sabendo em cada momento o que era esperado realizar, por isso não } \\
\text { senti dificuldades na forma de organizar o meu estudo. }\end{array}$ \\
\hline E25 & 54 & - & $\begin{array}{l}\text { Dificultou a orientação para a tarefa, porque não havia notificações das } \\
\text { participações que só acontecem quando seguimos uma determinada } \\
\text { pessoa. Como no grupo só uma pessoa é que me aceitou como amigo, } \\
\text { eu seguia o que era publicado por essa pessoa. Com os outras pessoas } \\
\text { tinha que estar atento sobre o que ia sendo comentado/publicado. }\end{array}$ \\
\hline
\end{tabular}

Fonte: Elaborado pelo autor deste artigo.

Como podemos ver na unidade de registro exemplificativa, o estudante E17 refere que a unidade curricular estava muito bem organizada no Facebook e que por isso não sentiu dificuldades em organizar-se para estudar os conteúdos.

A maioria dos testemunhos recolhidos sublinha essas vantagens do ponto de vista da gestão do tempo e do espaço na realização das e-tarefas, referindo que:

E1- "o ambiente de trabalho bem organizado permitiu-nos gerir bem as atividades" (UR30).

E14- "com o acompanhamento do professor foi possível fazer a organização e gestão das minhas atividades de forma eficaz" (UR43).

E20- "[...] o método permitiu-me organizar e gerir as atividades da disciplina de uma maneira mais adequada e corretamente em tempo útil" (UR49).

No entanto, como podemos ver na segunda unidade de registro exemplificativa, o estudante E25 aponta uma desvantagem, alertando para a questão da ausência de notificações quando os colegas da turma virtual não são adicionados como "amigos", situação esta que lhe dificultou o acompanhamento das discussões.

A terceira categoria, Confiança nas Capacidades, com vinte e nove registros, avalia a confiança que o estudante tem nas suas capacidades para desenvolver as e-atividades e na expressão das suas ideias nas salas de aula virtuais. A classificação das unidades de registro repartiram-se pelas frequências de Confiante $(+)$ e Pouco ou Nada Confiante (-). A primeira, Confiante, foi aquela que recebeu a maior parte das referências, dezessete registros, o que sugere que o Facebook tornou alguns destes estudantes mais confiantes nas suas capacidades; a segunda, Pouco ou Nada Confiante, com doze registros, revela que o ambiente em si nada contribuiu para aumentar a confiança nas capacidades. 
Quadro 3 - Confiança nas Capacidades

\begin{tabular}{|c|c|c|l|}
\hline EST & UR & S & \multicolumn{1}{|c|}{ Registro } \\
\hline E2 & 60 & + & $\begin{array}{l}\text { O ambiente fez-me crescer a confiança na utilização do Facebook e foi } \\
\text { um meio mais descontraído de aprender, isto é, senti menos o peso da } \\
\text { hierarquia, pois o professor teve uma postura de grande proximidade, } \\
\text { orientando as discussões, acompanhando-as e dando retorno daquilo que } \\
\text { dizíamos, e isso foi importante para expor as ideias sem receio. }\end{array}$ \\
\hline E15 & 73 & - & $\begin{array}{l}\text { Em termos gerais, não. Sempre existe o receio de estar de acordo com } \\
\text { o que se pede e ficar exposto e, consequentemente, constrangido com } \\
\text { a opinião alheia. Às vezes, se fosse somente a orientação do professor, } \\
\text { seria mais 'elegante' a maneira de receber correções. }\end{array}$ \\
\hline
\end{tabular}

Fonte: Elaborado pelo autor deste artigo.

Como podemos ver na primeira unidade de registro exemplificativa, o estudante $\mathrm{E} 2$, refere que o Facebook, como ambiente de aprendizagem mais descontraído, permitiu-lhe confiar mais nas suas capacidades, expondo as suas ideias sem medos e receios numa sala de aula virtual, onde se sentiu menos o peso da hierarquia e do poder.

Outros estudantes têm testemunhos idênticos, referindo também que:

E5- Sim. Na verdade, sinto-me bastante mais confiante e menos receoso na utilização desta ferramenta, mantendo, apesar disso, algumas reservas relativamente à confidencialidade e privacidade. Admito, no entanto, que quando usado com as devidas cautelas, estamos perante uma ferramenta que nos permite aumentar as nossas capacidades na exposição das nossas ideias. (UR63).

E17- Penso que o ambiente descontraído do Facebook permitiu-me expor as minhas opiniões e considerações de forma natural e espontânea; para esta participação também contribuíram os comentários do Professor a incentivar e problematizar os temas, bem como os comentários e 'gostos' dos colegas. (UR75).

E27- Saber gerir o stress e movimentar-me na utilização deste ambiente permitiu que adquirisse mais confiança nas minhas capacidades. (UR85).
No entanto, é de registar que não existe unanimidade nas perceções dos estudantes, já que, como podemos observar na segunda unidade de registro exemplificativa do Quadro 3, o estudante E15 refere que os seus índices de confiança não sofreram alterações com a lecionação da UC no Facebook, porque o constrangimento com as opiniões dos pares é algo que está sempre presente nestes ambientes.

Finalmente, relativamente à quarta categoria, Relação com os Colegas, igualmente com vinte e nove registros, que se refere à forma como se estabelece a integração na comunidade virtual de aprendizagem e com a perceção de confiança recebida da comunidade, a classificação das unidades de registro repartiu-se pelas frequências de Relação Fortalecida (+) e Relação Idêntica (-). A primeira, Relação Fortalecida, foi aquela que recebeu a maioria das referências, vinte e seis registros, o que sugere, sem dúvida, que o Facebook permitiu fortalecer os laços sociais entre os elementos da turma, formando uma comunidade de aprendizagem virtual de "amigos"; a segunda, Relação Idêntica, com apenas três registros, revela que a rede social não contribuiu para o fortalecimento de relações sociais com os colegas.

Quadro 4 - Relação com os Colegas

\begin{tabular}{|c|c|c|l|}
\hline EST & UR & S & \multicolumn{1}{c|}{ Registro } \\
\hline E2 & 89 & + & $\begin{array}{l}\text { O ambiente permitiu criar mais proximidade com os colegas, permitindo } \\
\text { também conhecer a página deles do Facebook e ter assim mais } \\
\text { informação sobre eles, descobrindo pontos comuns, o que faz aumentar } \\
\text { a sensação de que nos conhecemos. }\end{array}$ \\
\hline E27 & 114 & - & Não se verificaram alterações significativas na relação com os colegas. \\
\hline
\end{tabular}

Fonte: Elaborado pelo autor deste artigo. 
Como podemos ver na primeira unidade de registro exemplificativa, o estudante E2 refere que o Facebook permitiu criar a sensação de maior proximidade com os colegas. Outros estudantes sublinham as mesmas ideias, referindo também que:

E1- A minha relação com os colegas foi, sem dúvida, amplificada e melhorada neste ambiente de trabalho comparativamente ao fórum da sala de aula. (UR88).

E5- O relacionamento com os colegas tornou-se mais próximo e mais fácil, sendo que foi notória a intencionalidade do Professor desta UC ao 'exigir' que a turma se agrupasse e se relacionasse através desta rede social. Creio que o objetivo foi alcançado e, por isso, estamos todos de parabéns. (UR92).

E7- Penso que proporcionou um ambiente muito mais descontraído e, como tal, houve uma maior aproximação. (UR94).

E9- [...] o ambiente do tipo Facebook é muito importante para a interação entre colegas virtuais. Para o efeito criamos um (ou mais) grupo(s) no Facebook para interagirmos enquanto estudantes, de forma paralela, entre nós, em ambiente externo à UAb. (UR96).

E10- Foi sempre muito agradável a relação com os colegas, a possibilidade de ir comentando as intervenções que faziam e os comentários que eram emitidos sobre os meus 'posts' tornaram-nos a todos mais 'reais'. (UR97).

E12- Penso que foi uma forma agradável de me integrar no grupo. Aprendi bastante com os colegas e os desafios lançados, gostei de poder utilizar este espaço, contrariamente às minhas expectativas. Agradeço a oportunidade de crescer com o grupo [...] (UR99).

No entanto, registre-se que, apesar de não ser um testemunho que indica um mau relacionamento, a estudante E9 refere, como podemos ver na segunda unidade de registro exemplificativa, que o ambiente não produziu alterações significativas na relação com os colegas.

Na realidade, as salas de aula virtuais, nos LMS ou nas redes sociais, possibilitam diversos níveis de interação, que vão desde o um para um até de muitos para muitos. Estes níveis estão presentes em diferentes áreas do ambiente online e assumem diferentes tarefas, recursos e funções sociais e educativas. As interações, não só com o professor, mas também com os colegas, configuram-se, pois, como a base prática da aprendizagem em ambiente e tais interações estão fundamentadas pelas teorias de caráter construtivista e sociointeracionista, como já referimos anteriormente, uma vez que exigem a negociação de conflitos e a partilha de significados (MONTEIRO; MOREIRA, 2012).

\section{Conclusões}

A necessidade de acompanhar os desafios da sociedade contemporânea, em rede e digital, e de dar resposta às atuais exigências que são feitas ao ensino superior fez com que muitas instituições tenham procurado integrar o eLearning no processo pedagógico, quer em espaços com acesso restrito e reservados, quer em espaços abertos com "respiração".

Baseados, pois, nessa necessidade de construir salas de aula virtuais com "respiração", desenvolvemos a nossa prática letiva ancorada num modelo de aprendizagem relacionado com o desenvolvimento de comunidades de prática e de aprendizagem e com a resolução de problemas. E os resultados dessa prática, tendo em conta as percepções dos estudantes envolvidos, revelam que, efetivamente, as redes sociais como o Facebook podem ter efeitos muito positivos no autoconceito acadêmico dos estudantes do ensino superior, em termos das diferentes dimensões consideradas, quer seja em nível da sua motivação, da confiança nas suas capacidades, da organização das atividades ou da relação com os seus pares.

Com efeito, pudemos concluir que os estudantes consideraram que o ambiente online "desenhado" pelo professor no Facebook foi um fator motivacional determinante para o seu desempenho acadêmico. Ao destacarem a presença constante do professor nos diferentes espaços de comunicação do ambiente e os diferentes papéis assumidos (motivador, mediador, moderador...), ao salientarem a interação social existente entre estudantes e professor e entre pares e ao assumirem que este ambiente gerou discussões e conflitos cognitivos estimulantes, os estudantes acabam por revelar, indiretamente, que o modelo pedagógico virtual da Universidade Aberta fez emergir uma comunidade 
de aprendizagem que os motivou para as atividades acadêmicas da unidade curricular.

Concluímos também que os estudantes consideram que se esforçaram por cumprir as tarefas solicitadas pelo professor e que o Facebook é uma ferramenta que pode facilitar na organização e na gestão do tempo dispendido na realização das atividades acadêmicas.

No que diz respeito à questão da confiança nas capacidades, concluímos que o ambiente de aprendizagem tornou a maioria desses estudantes mais confiantes nas suas competências, e para essa confiança contribuíram, decisivamente, os espaços de discussão e comunicação por excelência da unidade curricular, criados quer no LMS, quer no Facebook. Como verificamos, na opinião da maioria dos estudantes estes espaços permitiram a troca de informação e discussão de assuntos e propiciaram a organização de debates de ideias com foco num tema preciso. Assim, este progresso na confiança das capacidades deve fazer-nos repensar e/ou redesenhar práticas sedimentadas apenas num contexto ou ambiente. Não tendo a intenção, nem a possibilidade, de prever e de esgotar todas as possibilidades tecnológicas a serviço da educação, ambientes digitais como os LMS e as redes sociais podem, hoje, ser combinadas no processo pedagógico num formato que apelidamos de blended e-learning. Através de plataformas interativas colaborativas próprias ou incorporadas em ambientes online de aprendizagem, as ferramentas da Web 2.0 podem propiciar espaços e condições técnicas para o desenvolvimento de comunidades de aprendizagem devido à sua versatilidade, facilidade de utilização e inúmeras possibilidades de comunicação, partilha e de colaboração.

Finalmente, relativamente à relação com os pares, concluímos que esse ambiente de aprendizagem permitiu fortalecer os laços sociais entre os elementos da turma, permitindo formar uma "consistente" comunidade de aprendizagem virtual de "amigos".

Para a formação dessa comunidade de prática foram decisivos os diferentes ambientes criados na web social com ferramentas da Web 2.0. Estes ambientes e as diferentes salas de aula virtuais criadas nestes cenários possibilitaram diversos níveis de interação, desde o um para um até de muitos para muitos. Para além disso, as interações, não só com o professor, mas também com os colegas, configuraram-se como a base prática da aprendizagem, e tais interações foram suportadas pelas teorias de caráter construtivista e sociointeracionista.

No entanto, temos de ter algumas reservas na leitura desses resultados, porque existem alguns aspetos que, quando não observados, podem constituir-se como limites à sua utilização, tais como: a facilidade de reprodução em massa e de apropriação de ideias originais, sem que se garantam os direitos de autor; o risco de banalização de conteúdos importantes; o overload de informações; a possibilidade de dispersão da atenção, causando a perda do objetivo e interesse pedagógico inicial; e a questão da segurança e da garantia de privacidade (HEW, 2011; WILSON; GOSLING; GRAHAM, 2013).

Concluímos referindo que com a crise da modernidade e da razão absoluta como a conhecemos, o ser humano pode usufruir da conectividade da "sociedade em rede" para, num ambiente de partilha e de interatividade e a partir da construção própria de significados, desenvolver-se como pessoa e como ser social (MOREIRA; JANUÁRIO; MONTEIRO, 2014).

O nosso estudo, em particular, permite verificar esse desenvolvimento como ser social, destacando a melhoria do autoconceito acadêmico dos estudantes do ensino superior quando se recorre a um processo pedagógico sustentado na educação a distância e no eLearning.

\section{REFERÊNCIAS}

BARDIN, L. L'analyse de contenu. Paris: PUF, 1977.

BASSO, M. et al. Redes sociais: espaço de aprendizagem digital cooperativo. Conjectura: Filosofia e Educação, v.18, n. 1, p. 135-149, 2013.

BENTO, F. Autoconceito e participação social do estudante do ensino superior. 1997. Dissertação (Mestrado em Educação) - Faculdade Psicologia Ciências da Educação, Coimbra, 1997. 
CASTELLS, M. A sociedade em rede. Do conhecimento à política. In: CASTELLS, M.; CARDOSO, G. (Org.) A sociedade em rede. Do conhecimento à acção política. Debates - Presidência da República. Lisboa: Imprensa Nacional, 2005.p.17-30. Disponível em: $<$ http://www.cies.iscte.pt/destaques/documents/Sociedade_em_Rede_CC.pdf $>$. Acesso em: 17 fev. 2014.

A sociedade em rede. A era da informação: economia, sociedade e cultura. Lisboa: Fundação Calouste Gulbenkian, 2007.

CHU, M.; MEULEMANS, Y. The problems and potencial of Myspace and Facebook usage in academic libraries. Internet Reference Services Quarterly, v. 13, n. 1, p. 69-76, 2008.

ESTEVÃO, C.; ALMEIDA, L. Prática desportiva e medidas de autoconceito físico e académico. In: ALMEIDA, L. S. et al (Ed.). Actas do IV Congresso Galaico-Português de Psicopedagogia. Braga: Universidade do Minho, 1998. p. 512-519.

GARRISON, D.; ANDERSON, T. El e-learning en el siglo XXI. Investigación e práctica. Barcelona: Octaedro, 2005. GOULÃO, M. Ensinar e aprender em ambientes online: alterações e continuidades na(s) prática(s) docente(s). In: MOREIRA, J. A.; MONTEIRO, A. (Org.). Ensinar e aprender online com tecnologias digitais: abordagens teóricas e metodológicas. Porto: Porto Editora, 2012. p. 77-98.

HEW, K. F. Student's and teacher's use of Facebook. Computers in Human Behaviour, v. 21, p. 662-676, 2011.

LEE, M.; McLOUGHLIN, C. Teaching and learning in the Web 2.0 era: empowering students through learnergenerated content. International Journal of Instructional Technology and Distance Learning, v. 4, n. 10, p. 21-34, 2007.

LIMA, M.; SECO, G. Autoconceito académico em adultos. Revista Portuguesa de Pedagogia, v. XXIV, p. 303$315,1990$.

MCLOUGHLIN, C.; LEE, M. Pedagogy 2.0: critical challenges and responses to Web 2.0 and social software in tertiary teaching. In: LEE, M.; McLOUGHLIN, C. (Ed.). Web 2.0 based e-learning: applying social informatics for tertiary teaching. Hershey: Information Science Reference, 2011. p. 43-69.

MILES, M.; HUBERMAN, A. Drawing valid meaning from qualitative data: toward a shared craft. Educational Researcher, v. 13, n. 5, p. 20-30, 1984.

MONTEIRO, A.; MOREIRA, J. A. O blended learning e a integração de sujeitos, tecnologias, modelos e estratégias de ensino-aprendizagem. In: MONTEIRO, A. et al (Coord.). Blended learning em contexto educativo: perspetivas teóricas e práticas de investigação. Santo Tirso: De Facto Editores, 2012. p. 33-58.

MOREIRA, J. A. (Re) Pensar o ensino com objetos de aprendizagem audiovisuais em ambientes presenciais e online. In: MOREIRA, J. A.; MONTEIRO, A. (Org.). Ensinar e aprender online com tecnologias digitais: abordagens teóricas e metodológicas. Porto: Porto Editora, 2012. p. 77-98.

MOREIRA, J. A.; MONTEIRO, A. O trabalho pedagógico em cenários presenciais e virtuais no ensino superior. Educação, Formação \& Tecnologias, v. 3, n. 2, p. 82-94, 2010.

MOREIRA, J. A.; JANUÁRIO, S.; MONTEIRO, A. Educar na rede social. In: MOREIRA, J. A.; BARROS, D.; MONTEIRO, A. (Org.) Educação a Distância e eLearning na Web Social. Santo Tirso: Whitebooks-CEIS20, 2014. p. 23-38.

OKADA, A. Competências-chave para coaprendizagem na era digital. Fundamentos, métodos e aplicações. Santo Tirso: Whitebooks, 2014.

PEMPECK, A.; YERMOLAYEVA, A.; CARVET, L. College students'social networking experiences on Facebook. Journal of Applied Developmental Psychology, n. 30, p. 227-238, 2009.

RECUERO, R. Redes sociais na internet. Porto Alegre: Sulina, 2009.

SALMON, G. E-tivities: the key to teaching and learning online. Londres: Routledge, 2003.

SCHOEDER, J.; GREENBOWE, T. The chemistry of Facebook: using social networking to create an online community for the organic chemistry. Innovate: Journal of Online Education, v. 5, n. 4, p. 22-31, 2009.

SIMÕES, M.; SERRA, A. A importância do auto-conceito na aprendizagem escolar. Revista Portuguesa de Pe- 
dagogia, v. 21, p. 233-252, 1987.

URHAHNE, D. et al. Academic self-concept, learning motivation, and test anxiety of the underestimated student. British Journal of Educational Psychology, n. 81, p. 161-177, 2011.

VALA, J. A análise de conteúdo. In: SILVA, A.; PINTO, J. (Org.). Metodologia das Ciências Sociais. Porto: Edições afrontamento, 1986.

VEIGA, F. Estudo de um instrumento de autoconceito escolar: "Self-concept as a learner scale". In: GONÇALVES, M. et al (Eds.). Avaliação psicológica: formas e contextos. Braga: APPORT, 1996. p. 365-380.

WANG, F.; HANNAFIN, M. J. Design-based research and technology-enhanced learning environments. Educational Technology Research and Development, v. 53, n. 4, p. 5-23, 2005.

WILSON, R. E.; GOSLING, S. D.; GRAHAM, L. T. Review of Facebook research in the social sciences. Perspectives on Psychological Science, v. 7, n. 3, p. 203-220, 2013.

Recebido em: 10.08.2015

Aprovado em: 01.10 .2015 